\title{
Processo formativo de professores para a Educação Inclusiva subsidiado pelo Desenho Universal para a Aprendizagem
}

\author{
Jacqueline Lidiane de Souza Prais ${ }^{1}$ \\ Celia Regina Vitaliano ${ }^{2}$
}

\begin{abstract}
RESUMO
O aprimoramento do trabalho pedagógico, desenvolvido pelos professores na classe comum, representa uma condição essencial para favorecer práticas pedagógicas inclusivas. Nesse sentido, o Desenho Universal para a Aprendizagem (DUA) consiste em uma abordagem curricular para a educação inclusiva. Este artigo tem o objetivo de descrever um processo formativo desenvolvido junto a professoras atuantes nos anos iniciais do Ensino Fundamental, visando o desenvolvimento de práxis inclusivas subsidiadas nos princípios do DUA, por meio de uma pesquisa colaborativa. Três docentes participaram do processo. A coleta dos dados ocorreu durante o desenvolvimento de práticas reflexivas, planejamentos colaborativos e participações da pesquisadora em sala de aula. Constatou-se que o processo formativo, subsidiado pelo DUA e aliado aos procedimentos da pesquisa colaborativa, favoreceu o aprimoramento na qualidade do ensino, evidenciado nas mudanças ocorridas nos planos de aulas e nas práticas pedagógicas efetivas das docentes.
\end{abstract}

PALAVRAS-CHAVE: Formação de professores. Educação Inclusiva.

Prática Pedagógica. Desenho Universal para a Aprendizagem.

Pesquisa colaborativa.

\footnotetext{
${ }_{1}^{1}$ Doutora em Educação. Universidade Estadual de Londrina (UEL), Londrina, Paraná, Brasil. Orcid: https://orcid.org/0000-0002-3658-7021.E-mail: jacqueline_lidiane@hotmail.com.

${ }^{2}$ Doutora em Educação. Universidade Estadual de Londrina (UEL), Londrina, Paraná, Brasil. Orcid: https://orcid.org/0000-0002-8757-4204. E-mail: reginavitaliano@gmail.com.
} 
Education Process of Teachers for Inclusive Education subsidized by the Universal Design for Learning

\begin{abstract}
The improvement of the pedagogical work developed by teachers in common classes represents an essential condition to favor inclusive pedagogical practices. In this sense, the Universal Design for Learning (UDL) consists of a curricular approach to inclusive education. This article aims to describe an education process developed with female teachers working in the early years of elementary school, aiming at the development of inclusive practices subsidized on the guiding principles of UDL, through a collaborative research. Three female teachers took part in the process. The data collection took place during the development of reflective practices, collaborative planning, and the participation of the researcher in the classroom. It was verified that the education process, subsidized by the UDL allied to the procedures of the collaborative research, favored the improvement in the quality of teaching, evidenced in the changes occurred in the lesson plans and in the effective pedagogical practices of the teachers.
\end{abstract}

KEYWORDS: Teacher education. Inclusive Education. Pedagogical Practice. Universal Design for Learning. Collaborative research.

Proceso formativo del profesorado para la educación inclusiva subvencionado por el Diseño Universal para el Aprendizaje

\title{
RESUMEN
}

La mejora del trabajo pedagógico desarrollado por los profesores en el aula común representa una condición esencial para promover las prácticas pedagógicas inclusivas. En este sentido, el Diseño Universal para el Aprendizaje (DUA) consiste en un abordaje curricular para la educación inclusiva. Este artículo pretende describir un proceso formativo desarrollado con profesores que trabajan en los primeros años de la escuela primaria con el objetivo de desarrollar prácticas inclusivas subvencionadas en los principios del DUA a través de una investigación colaborativa. Tres profesores fueron los que participaron en el proceso. La recolección de datos se produjo durante el desarrollo de las prácticas reflexivas, planificaciones colaborativas y la participación de la 
investigadora en la sala de clases. Se constató que el proceso formativo, subvencionado por el DUA, combinado con los procedimientos de investigación colaborativa, favoreció la mejora de la calidad de la enseñanza, evidenciada en los cambios que se produjeron en los planes de clase y en las prácticas pedagógicas efectivas de los profesores.

DESCRIPTORES: Formación de profesores. Educación inclusiva. Práctica pedagógica. Diseño Universal para el Aprendizaje. Investigación en colaboración.

\section{Introdução}

A adequação da estrutura física, a formação dos recursos humanos, a elaboração e aquisição de recursos didáticos e as práticas pedagógicas adequadas às necessidades de aprendizagem dos estudantes têm sido considerados os aspectos primordiais para a efetivação da educação inclusiva (OMOTE, 2013; VITALIANO, 2019).

Fundamentada no princípio da educação como direito de todos, a inclusão escolar incide em desafios para a organização do trabalho pedagógico que passa a ter como ponto de partida a diversidade em sala de aula em detrimento da homogeneidade no processo de aprendizagem (LUSTOSA, 2019).

Nesse contexto, a busca pelo aprimoramento da organização e da condução do trabalho pedagógico, realizado pelos professores das classes comuns no ensino regular, representa uma condição essencial para favorecer o desenvolvimento de práticas pedagógicas inclusivas.

Dessa maneira, a abordagem curricular proposta pelo Desenho Universal para a Aprendizagem (DUA) consiste em uma referência e possibilidade para a ação didática e a formação docente com vista ao desenvolvimento de práxis inclusivas (MEYER; ROSE; GORDON, 2002). Comumente, compreendemos que práxis corresponde ao movimento dialético existente entre a teoria e a prática por meio da investigação da ação educativa e intervenção nela, ou seja, o processo em que se 
consolida por meio de um "vaivém da ação-reflexão sistemático e continuado feito pelo professor" (SÁNCHEZ, 2005, p. 139).

Considerando a existência de um corpo de conhecimentos desenvolvidos na área de Arquitetura, denominado Desenho Universal, o qual buscava favorecer o acesso a um maior número de pessoas à diferentes ambientes, à comunicação e à informação, na década de 1990 os pesquisadores da área da educação, Anne Meyer, David Rose e David Gordon fundamentados no referido conceito, se uniram a um grupo de pesquisadores nos Estados Unidos do Center for Applied Special Technology (CAST) e propuseram pressupostos curriculares para subsidiar o planejamento e a prática docente em uma perspectiva inclusiva, denominado Desenho Universal para a Aprendizagem (DUA) - em inglês - Universal Design for Learning (UDL) (MEYER; ROSE; GORDON, 2002; CAST, 2011).

Essa proposta apresenta uma abordagem curricular para a implementação da educação inclusiva que tem o intuito de remover possíveis barreiras de acesso ao currículo escolar (PRAIS, 2020). Além disso, considera que o ensino deve ser organizado a partir da flexibilidade e da acessibilidade, a fim de que um maior número de alunos aprenda (MEYER; ROSE; GORDON, 2002). Tal concepção assume que, mais do que intenções, são necessárias práticas inclusivas que efetivem os princípios de um ensino para assegurar a aprendizagem dos alunos, bem como, satisfaça as necessidades educacionais dos alunos.

O DUA assume como princípios norteadores: Princípio 1 - possibilitar múltiplas formas de apresentação do conteúdo, de ação e de expressão do conteúdo pelo aluno, Princípio 2 - proporcionar vários modos de aprendizagem e desenvolvimento organizados pelo professor para os alunos e, Princípio 3 - promover a participação, o interesse e o engajamento, na realização das atividades pedagógicas (MEYER; ROSE; GORDON, 2002).

Assim, é preciso entender que, numa abordagem de educação subsidiada por essa perspectiva, a diversidade e a diferença entre os estudantes são vistas como orientadoras das práticas pedagógicas, da 
organização dos objetivos, materiais, métodos e da avaliação do professor e visam à aprendizagem e o envolvimento de todos em sala de aula (MEYER; ROSE; GORDON, 2014).

Lustosa (2019) sugere que o DUA seja apresentado como uma das novas formas de ensino que pode ampliar as possibilidades de aprendizagem e participação dos alunos com NEE, a partir da concepção de deficiência defendida pelo modelo social, compreendendo a heterogeneidade do alunado e a inadequação das práticas baseadas na uniformização curricular.

Conforme a proposta do DUA, as possibilidades didáticas para ensino um determinado conteúdo ou conceito revelam que, comumente, a dificuldade não está fixada no aluno, mas nos caminhos que não são oferecidos a eles para aprenderem e terem acesso à aprendizagem (NUNES; MADUREIRA, 2015). Nesse sentido, “a diversificação de estratégias pode contribuir para que o aluno consiga demonstrar os conhecimentos aprendidos" (ZERBATO; MENDES, 2018, p. 152).

Segundo Nunes e Madureira (2015, p. 133), a perspectiva do DUA é uma abordagem curricular, pois tem por finalidade "minimizar as barreiras da aprendizagem e maximizar o sucesso de todos os alunos". Dessa forma, cabe ao professor analisar as limitações na gestão do currículo para proporcionar o acesso a ele considerando as características de todos seus alunos (MORNINGSTAR et al., 2015).

De tal modo, este artigo tem o objetivo de descrever um processo formativo desenvolvido junto a professoras atuantes nos anos iniciais do Ensino Fundamental, visando o desenvolvimento de práxis inclusivas com base nos princípios do DUA, por meio de uma pesquisa colaborativa.

\section{Método}

Esta investigação científica foi desenvolvida a partir dos procedimentos formativos indicados pela pesquisa colaborativa, conforme Ibiapina (2008). Este tipo de pesquisa alia a produção de saberes e a 
formação contínua de professores por meio do estudo de questões práticas e teóricas desencadeando processos de estudos frente aos problemas e as necessidades do agir profissional no contexto escolar (IBIAPINA, 2008).

Somando a isso, o principal objetivo deste tipo de pesquisa é "aprofundar a compreensão e interpretação da prática docente com a intenção de fortalecer, isto é, dar mais poder (empowerment) para que esses profissionais possam se emancipar" (IBIAPINA, 2008, p. 11).

A pesquisa colaborativa foi desenvolvida em uma instituição pública municipal que continha 13 professoras atuantes nos anos iniciais do Ensino Fundamental localizada em uma cidade do Norte do Paraná que atendia, em média, 122 alunos no ano de 2019. A pesquisa e seus procedimentos foram aprovados pelo Comitê de Ética em Pesquisa pelo Parecer $n^{\circ}$ 3.079.090.

Esclarecemos que foram desenvolvidas quatro estratégias de formação, propostas por Ibiapina (2008), junto as professoras participantes: 1) os ciclos de estudos teóricos com as 13 participantes; 2) práticas reflexivas; 3) planejamento colaborativo e; 4) participação da pesquisadora em sala de aula, sendo essas últimas três estratégias realizadas, apenas com quatro docentes, em virtude de exigir da pesquisadora uma atenção mais individualizada. Neste artigo serão apresentados os resultados advindos das estratégias formativas desenvolvidas com as três docentes, muito embora os conteúdos estudados nos ciclos de estudos (estratégia coletiva) tenham sido retomados nas sessões reflexivas e de planejamento.

Após a sensibilização das docentes para participação na pesquisa, foi realizado o levantamento de suas necessidades formativas em relação ao desenvolvimento de práticas pedagógicas inclusivas junto aos alunos com Necessidades Educacionais Especiais (NEE). Todas as participantes se interessaram em participar da pesquisa. O critério para selecionar as três participantes dentre as 13 foi o de ter maior número de alunos público alvo da Educação Especial (PAEE), com maior nível de dificuldades de aprendizagem, em sua turma. A seguir, apresentamos no 
Quadro 1, a identificação das professoras colaboradoras selecionadas e a descrição dos alunos por elas atendidos.

Quadro 1: Quadro de descrição dos alunos atendidos pelas professoras colaboradoras

\begin{tabular}{|c|c|c|c|c|c|c|c|}
\hline $\mathbf{P}$ & Turma & $\begin{array}{c}\mathrm{N}^{\mathbf{0}} \\
\text { alunos }\end{array}$ & $\begin{array}{l}\mathrm{N}^{\circ} \text { de } \\
\text { alunos } \\
\text { com } \\
\text { NEE }\end{array}$ & & $\begin{array}{l}\text { Alunos } \\
\text { AEE/Diagnóstico }{ }^{3}\end{array}$ & \multicolumn{2}{|c|}{$\begin{array}{c}\text { Alunos APA / queixa } \\
\text { escolar }\end{array}$} \\
\hline $2 \mathrm{~A}$ & $2^{\circ}$ ano $\mathrm{A}$ & 21 & 5 & 3 & $\begin{array}{c}\text { PAEE1- Transtorno } \\
\text { Déficit de Atenção e } \\
\text { Hiperatividade } \\
\text { (TDAH) } \\
\text { PAEE2 - TDAH, } \\
\text { Transtorno Opositor } \\
\text { Desafiador (TOD) e } \\
\text { Transtorno do Humor. }\end{array}$ & 3 & $\begin{array}{l}\text { APA1, APA2 e APA3 } \\
\text { Dificuldade de } \\
\text { atenção e de reter } \\
\text { conteúdo. }\end{array}$ \\
\hline B & $2^{\circ}$ ano $\mathrm{B}$ & 20 & 6 & 1 & PAEE3 - TDAH. & 5 & $\begin{array}{c}\text { APA4, APA5, APA6, } \\
\text { APA7 e APA8 } \\
\text { Dificuldade de } \\
\text { atenção e de reter } \\
\text { conteúdo. }\end{array}$ \\
\hline $4 \mathrm{~A}$ & $4^{\circ}$ ano $\mathrm{A}$ & 21 & 6 & 3 & $\begin{array}{c}\text { PAEE8 - TDAH } \\
\text { associado à dislexia } \\
\underline{\text { PAEE9 }} \text { - Transtorno } \\
\text { do Desenvolvimento } \\
\text { Intelectual } \\
\underline{\text { PAEE10 - Deficiência }} \\
\text { Auditiva (DA). }\end{array}$ & 3 & $\begin{array}{l}\text { APA14, APA15 e } \\
\text { APA16 } \\
\text { Dificuldade de } \\
\text { atenção e de reter } \\
\text { conteúdo. }\end{array}$ \\
\hline
\end{tabular}

Fonte: Elaborado pelas autoras (2021)

A coleta de dados se deu durante os meses de abril a novembro do ano de 2019, nos quais foram realizadas as três estratégias formativas desenvolvidas com P2A, P2B e P4A. Utilizamos essa sigla para se reportar a $\mathrm{P}$ como professora seguida da indicação da turma em que atuava na classe comum.

Em relação as estratégias formativas desenvolvidas junto as três participantes, ao todo foram elaborados 146 planos de aula em colaboração com a pesquisadora sendo: 52 com P2A, 52 com P2B e 42 com $\mathrm{P} 4 \mathrm{~A}$, os quais foram implementados na sala de aula das professoras e fizeram parte dos momentos de participação colaborativa da pesquisadora, que foram 25 com P2A, 26 com P2B e 22 com P4A, totalizando 73 sessões. Seguidos de 73 práticas reflexivas e (re)

\footnotetext{
3 Utilizamos o sublinhado para indicar os alunos que estavam matriculados na Sala de Recursos Multifuncionais - Tipo 1 nos meses de fevereiro e março de 2019.
} 
planejamento, sendo 25 com P2A, 26 com P2B e 22 com P4A, nas quais as professoras colaboradoras refletiram sobre suas práticas pedagógicas em sala de aula, nas quais a pesquisadora participou de forma colaborativa.

Foram utilizados como instrumentos de coleta de dados: notas de campo, protocolo de registro das observações em sala de aula, roteirização para a análise do planejamento, roteirização para o planejamento colaborativo e, ferramenta com questões norteadoras para as práticas reflexivas. E para análise dos dados definimos como técnica a análise de episódios, conforme Moura (2004).

\section{Resultados e discussão}

Os resultados serão apresentados por meio da descrição do processo formativo desenvolvido com cada uma das professoras colaboradoras, ilustrado por episódios ocorridos durante o processo de formação colaborativa.

\section{(i) Desenvolvimento das estratégias formativas junto a P2A}

P2A era licenciada em Pedagogia e em História, especializada em Psicopedagogia Clínica e Institucional, em Educação Especial e em Educação de Jovens e Adultos. No ano de 2019 em que foi desenvolvida a pesquisa, estava cursando o Mestrado em Ensino, tinha 41 anos de idade e 12 anos de experiência como docente, tendo atuado também como Pedagoga e Professora de SRM - T1 desde a Educação Infantil, anos iniciais e anos finais do Ensino Fundamental e Ensino Médio.

P2A em determina ocasião apresentou a reflexão de que era comum realizar as mesmas atividades a cada ano letivo, tal como, usar o livro didático apenas, mas que considerava que isso era insuficiente declarando "Aí o que acontece todo ano é a mesma coisa", "Aí, logo pensamos: sei lá podíamos fazer mais alguma coisa, além do livro sabe. 
Não deixando o livro, mas trabalhar mais alguma coisa legal com eles". Somado a isso, P2A reconheceu que a proposta do DUA, estudada nos ciclos de estudos, possibilitou acompanhar de uma maneira melhor o desempenho dos alunos, refletindo que "eles estavam mais concentrados sabe, fomos fazendo juntos a atividade. E, aí todos acompanharam, um ou outro tinha dificuldade mais ali, mas foi tranquilo". Tal pressuposto é indicado por Sebastian-Heredero (2018) que reafirma a necessidade deste olhar sobre as características dos estudantes para organização da prática pedagógica inclusiva.

Selecionamos, dentre os planos de aula elaborados e implementados colaborativamente com P2A, àquele que tratou dos conteúdos de legenda, planta baixa e figuras planas envolvendo o ensino de Língua Portuguesa, Geografia e Matemática.

Neste planejamento de ensino P2A, inicialmente a docente realizou uma roda de conversa para o levantamento de elementos que compõem a sala de aula e, concomitantemente, esses dados foram registrados em uma cartolina fixada no quadro, para melhor visualização de todos os alunos, utilizando canetas coloridas (uma cor para cada item).

Em seguida, elaborou coletivamente a legenda para cada elemento que compõe a sala de aula contando com a participação e o auxílio dos alunos na escolha da cor, na escrita, na colagem, na verificação dos elementos e na leitura coletiva deles, considerando que alguns estudantes eram alfabetizados e outros estavam em processo do domínio da leitura.

Posteriormente, a partir da legenda dos elementos contidos na sala de aula, a docente foi organizando a planta baixa em cartaz para melhor visualização de todos e também cada aluno recebeu um esboço para seu registro individual da sala de aula (Ver Figura 1).

Após isso, a professora pediu para que cada aluno identificasse sua posição na sala de aula na planta baixa apontando, descrevendo e escrevendo seu nome no cartaz e em seu registro individual. 
Por fim, P2A realizou uma avaliação oral por meio de questões norteadoras: O que registramos neste cartaz? Como elaboramos? O que é uma planta baixa? Como vocês conseguiram identificar o lugar de vocês neste desenho?

Figura 1: Planta baixa coletiva com os alunos do $2^{\circ}$ ano e planta baixa individual de PAEE1

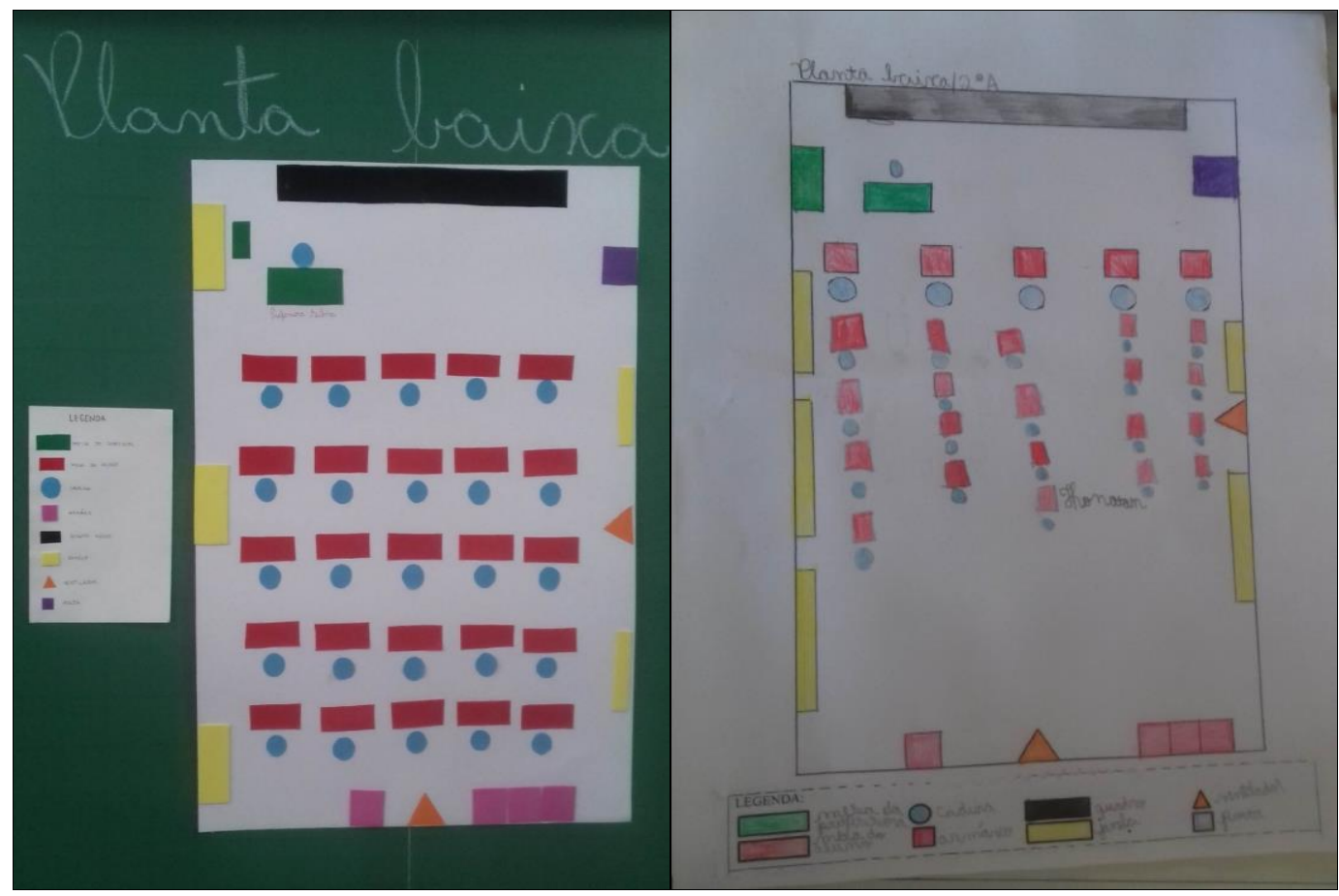

Fonte: Nota de campo da pesquisadora (2019)

Desse modo, o plano supracitado foi organizado e implementado em etapas minuciosamente detalhadas a fim de proporcionar a participação e aprendizagem dos alunos. Além disso, a docente possibilitou aos alunos utilizar as figuras planas e as cores para construção de legendas permitindo a aplicação e a associação de dois conteúdos durante a explicação e a realização da atividade. Propôs a articulação de atividades individuais e coletivas durante as aulas nas quais os alunos expressassem sua aprendizagem por meio de atividade escrita, oral, construção de cartaz coletivo e planificação individual. 
Na participação colaborativa em sala de aula com P2A, identificamos também na aplicação deste plano que a previsão das atividades foi atrelada a necessidade do acompanhamento coletivo e individual na realização das tarefas e a promoção da cooperação entre os alunos nas atividades. Percebemos que a docente, durante a aula, ao promover estratégias de interesse e engajamento, permitiu que os alunos colaborassassem uns com outros favorecendo que os alunos com NEE fosse atendidos em suas dúvida com o auxílio dos próprios colegas ou da professora.

Ressaltamos também, que P2A valorizou as ideias dos alunos como ponto de partida para o estudo e assim deu atenção às singularidades dos alunos com NEE verificando se estavam entendendo a proposta das atividades e realizando as tarefas junto com a turma. Ao favorecer a avaliação oral em detrimento apenas da forma escrita a docente contemplou a necessidade de PAEE1 e APA1 que não eram alfabetizados, mas que na linguagem oral puderem expressar aquilo que estavam aprendendo inclusive apontando para o recurso didático (planta baixa indivual) os elementos que compunhavam a sala e sua localização naquele espaço.

Além disso, ao final da aula, na realização da síntese de estudo para sistematização do conceito de aprendizagem da aula, observamos que os alunos com NEE de P2A foram os que mais participaram relatando e descrevendo cada momento da aula, e os demais alunos complementaram com suas ideias do conceito de planta baixa, como a sala estava organizando e a docente foi mediando cada apontando e intigando a participação de mais alunos realizando questionamentos direcionados as atividades feitas durante a aula.

Desse modo, apreendemos que P2A planejou e implementou essas estratégias pedagógicas inclusivas, partindo do reconhecimento dos diferentes níveis de aprendizagem de seus alunos e das necessidades que eles apresentavam, conforme nos indica a abordagem curricular do DUA (MEYER; ROSE; GORDON, 2014). 
Destacamos nesse plano de aula que foram previstos recursos acessíveis e possibilidades de interação entre os alunos, a fim de promover o envolvimento de todos e tornar uma aprendizagem ativa. De tal modo, os recursos são entendidos como meio que possibilitam e potencializam a aprendizagem de todos os alunos, principalmente dos estudantes com NEE (MEYER; ROSE; GORDON, 2014; PRAIS, 2017).

Com base nesses pressupostos, após aplicação deste plano de aula na prática pedagógica, P2A declarou que os alunos com NEE conseguiram realizar as atividades propostas de forma mais independente, sublinhando que PAEE1 auxiliou colegas a indicarem sua posição na planta baixa, se propôs a auxiliar a professora durante a construção da legenda e da planta baixa e apresentou, oralmente, uma aprendizagem do conceito condizente aos objetivos previstos para aula.

P2A: Essa aula mostrou para mim o quanto é importante essa construção do conceito ao longo da aula. Foi muito bom para turma toda, ir passo a passo construindo, primeiro o que tem na sala, depois a legenda foi muito bom construir com eles, e em seguida montar com eles a planta. Se eu tivesse levado pronta, apenas para mostrar o que é uma planta baixa, aposto que não faria sentido. E a realização dessa atividade foi além do que eu imaginei, ele discutindo, não essa janela é mais para cá, porque a porta fica mais para cá. Uma noção de espaço surpreendente, inclusive aqueles com NEE foram os que mais surpreenderem. A fala deles é muito boa, por isso múltiplas formas, né. Porque se fosse só escrita eles não iam conseguir fazer sozinhos, e não iam entender nada.

Interpretamos que P2A indicou que o processo de planificação do conteúdo (materializado no cartaz com a planta baixa) favoreceu o engajamento dos alunos e múltiplas formas de apresentação do conteúdo e de ação e expressão de aprendizagem pelos alunos. Somado a isso, a professora colaboradora indicou que a atividade satisfez às NEE apresentadas por seus alunos, durante as possibilidades didáticas que foram propiciadas.

Avaliamos que o programa de formação possibilitou a ela se mobilizar para organizar atividades diferenciadas com base nas necessidades de sua 
turma e possibilitaram a vivência prática com o conteúdo, conforme indicação nos princípios do DUA, tanto na apresentação do conteúdo como na representação da aprendizagem (MEYER; ROSE; GORDON, 2014).

\section{ii) Desenvolvimento das estratégias formativas junto a P2B}

P2B, licenciada em Pedagogia e especializada em metodologias de ensino, tinha 52 anos de idade e 17 anos de experiência profissional como professora em Centro de Atendimento Especializado na Área da Deficiência Visual, Educação Infantil e Anos iniciais do Ensino Fundamental.

Notamos que, a principal dificuldade, relatada pela docente e observada em sala de aula, era em relação às estratégias de ensino e uso de recursos didáticos. Ela demonstrava domínio curricular e atenção às necessidades de aprendizagem de seus alunos. Todavia, mesmo especializada na área de metodologias de ensino, carecia de conhecimento de estratégias diferenciadas e materiais pedagógicos que pudessem ser utilizados no ensino de determinados conteúdos, visto que recorria a organização de aulas tradicionais conforme observado na maioria das vezes em que a acompanhamos em sala de aula na fase de levantamento das necessidades de formação. No episódio a seguir, P2B demonstrou a preocupação com a aplicação do terceiro princípio do DUA (múltiplas formas de engajamento).

Quadro 2: Episódio de Planejamento colaborativo com P2B - 22/10/2019

P2B: Aqui nessa atividade quando eu coloco assim: levantamento de hipóteses junto aos alunos. Ai é possível entender que também estou tentando o terceiro princípio?

P: Sim, pois no princípio das formas de promover o interesse e o engajamento está junto com os outros dois, pois será o modo que você apresenta o conteúdo e que possibilita eles apresentarem se aprenderam o conteúdo.

P2B: Então, era bem o que eu tinha pensado. Porque aqui é ainda apresentação do conteúdo que vou fazer uma pergunta para eles - porque temos que trabalhar? - então, a partir do que eles forem falando eu vou até anotar sabe para não esquecer as pérolas que vão sair (risos). Enquanto é uma forma de introduzir o conteúdo estou estimulando a participação deles.

Fonte: Notas de campo da pesquisadora (2019) 
Durante a elaboração deste planejamento, identificamos que P2B reconheceu que a aplicação do terceiro princípio (múltiplas formas de engajamento) está articulada aos dois primeiros (múltiplas formas de apresentação e múltiplas formas de ação e representação), pois exige a organização de atividades que considerem a participação dos alunos. Tal preceito é exposto por Rose, Meyer e Gordon (2002) esclarecendo que se a atividade não prevê a participação dos alunos todos os princípios estão comprometidos.

A seguir, apresentamos a descrição de um plano de aula elaborado com P2B contemplando o conteúdo de Tratamento da informação, Construção de tabela e gráfico (Ver Figura 2), Noções de medida, utilizando uma receita de gelatina envolvendo conteúdos das disciplinas de Matemática e Língua Portuguesa.

Figura 2: Tabela e gráfico contendo o sabor preferido dos alunos do $2^{\circ}$ ano B
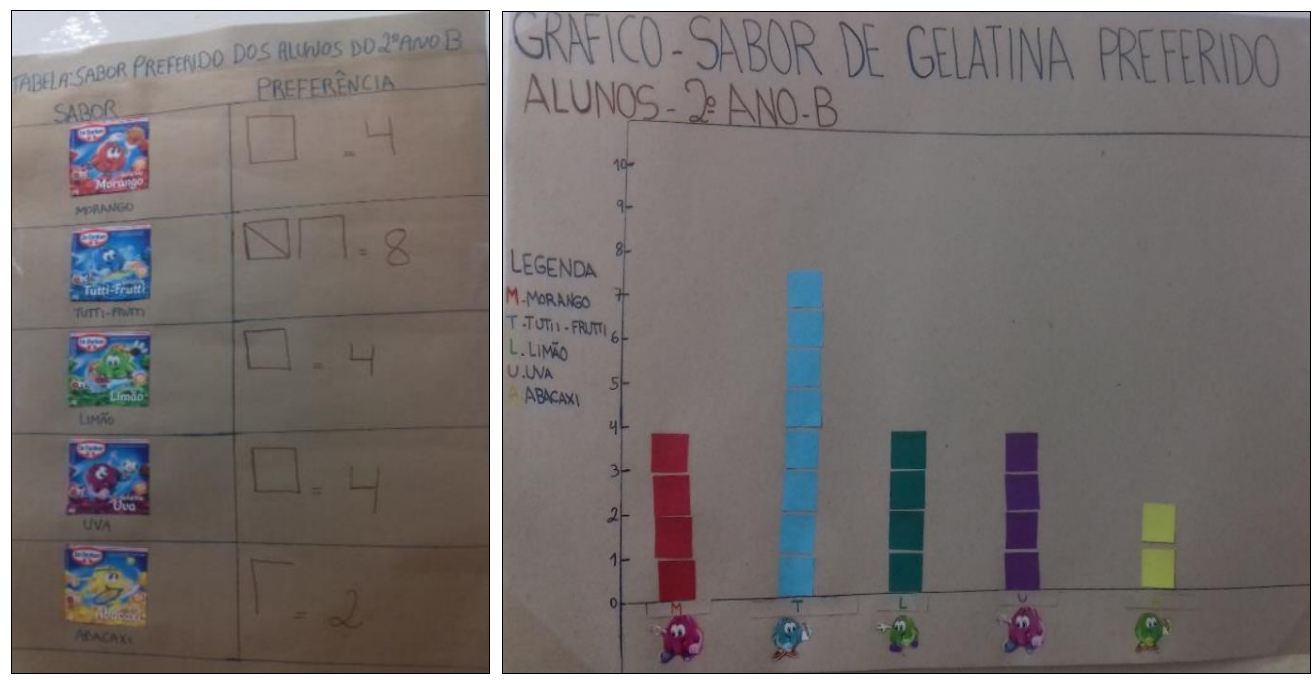

Fonte: Elaborados por P2B e seus alunos (2019)

Neste planejamento, P2B construiu a seguinte proposta de atividades: Disponibilizou aos alunos um texto impresso contendo uma receita de gelatina iniciando a aula explicando aos alunos que se tratava de uma receita e solicitou a leitura do texto de modo coletivo pelos alunos. 
$\mathrm{Na}$ sequência fez o reconhecimento dos elementos estruturantes do gênero receita e seu objetivo tendo como apoio visual o texto impresso que havia entregue aos alunos no início da aula.

Considerando os diferentes níveis de alfabetização na turma, P2B propôs a leitura coletiva e, assim, foi verificando com os alunos com mais dificuldades algumas palavras-chave no texto e os auxiliou na leituras das palavras: gelatina, colher, água, copo, entre outras.

$\mathrm{Na}$ sequência etapa da aula, junto com o alunos a professora, sugeriu fazerem cinco sabores de gelatina diferentes, com cores diferentes. Nesse momento, buscou levar os alunos a identificarem as unidades de medida e utensílios para medir água e a quantidade da gelatina (copo medidor em ML).

Após essa fase e esperar as gelatinas ficarem consistentes, os alunos degustaram as gelatinas e avaliaram suas preferências de sabor, associando a cor ao sabor escolhido. Nesse momento, foi possível identificar as preferências de cada um.

Depois de degustarem a gelatina, P2B propôs a elaboração de uma tabela para registrar o sabor de preferência de cada aluno em um cartaz (cartolina branca, embalagem das gelatinas, canetas coloridas) e cada aluno recebeu materiais para organizar sua tabela em uma folha sulfite em que iria registrar cada dado concomitantemente com a escrita coletiva da tabela em cartaz (Ver Figura 2).

Depois disso, propôs a leitura e análise da tabela a partir de questões interpretativas, tais como: o que registramos neste cartaz? O que possui nesta coluna? E na outra? Qual o sabor preferido dos alunos? E qual sabor os alunos menos preferiram?.

$\mathrm{Na}$ sequência, propôs a construção de um gráfico, por meio das mesmas estratégias utilizadas na construção da tabela (Ver Figura 2). Ao final propôs a realização de uma roda de conversa sobre as atividades realizadas evidenciando os elementos estruturantes do gênero textual receita, tratamento de informação e construção de tabela e gráfico. 
Neste plano de aula, identificamos que a professora aplicou os princípios do DUA em vários momentos, dentre eles destacamos: a disposição da sala (em forma de "U”), vivência prática com o conteúdo (realização e degustação da receita de gelatina), realização de atividades a partir de ideias apresentadas pelos alunos (preferência dos alunos pelo sabor), atividades que envolveram a participação ativa deles (a participação é essencial em cada etapa do plano de aula), construção textual de legenda com apoio das embalagens e de cores para representação do sabor para auxiliar aqueles que não liam ainda e os demais com dificuldade na leitura.

$\mathrm{Na}$ aula, observamos que os alunos que apresentavam NEE buscaram se apoiar na realização coletiva (cartaz construído e fixado no quadro) para fazer seu registro individualmente (folha sulfite), pois demonstravam insegurança em registrar os números e informações solicitados.

Ao final da atividade, oralmente ou por escrito, percebemos que todos eles, com NEE e sem NEE, conseguiram desenvolver a atividade com autonomia, exigindo pouco suporte individualizado e respondendo de forma adequada as questões sobre os dados.

Dentre eles, destacamos APA6 que, mesmo não dominando a leitura, se envolveu nas atividades, expondo suas ideias sempre que a professora questionava sobre os dados da tabela e do gráfico. Além disso, ele entendeu e auxiliou na realização das atividades, dizendo a professora: "é professora, usa esse copo porque nele tem o número para você quanto de água tem que por. Senão dá errado a receita", "Professora quase ninguém gosta de abacaxi, porque é azedo".

Sublinhamos que esse plano de aula contemplou a previsão de recursos acessíveis e possibilitou interações entre os alunos, a fim de promover o envolvimento de todos e tornar a aprendizagem ativa. Esses dados refirmam a ideia defendida por Meyer, Rose Gordon (2014) visto que os recursos didáticos utilizados na aula foram essenciais para os alunos com NEE e se demonstraram adequados para todos os 
estudantes. Tal pressuposto pode ser identificado nesta aula de P2A, visto que previu e proveu recursos acessíveis, favorecendo múltiplas representações do contéudos, forneceu múltiplas formas dos alunos expressarem sua aprendizagem e também utilizou estratégias de engajamento e envolvimentos dos alunos durante as atividades.

Após a implementação deste plano de aula, P2B avaliou que os discentes, em especial, aqueles com NEE conseguiram atingir os objetivos, devido às oportunidades de acesso ao conteúdo, propiciadas na atividade.

P2B: Olha, eu percebi que normalmente eu fazia assim. Dava o texto para ler, uns liam, outros, não, aí já fazia a leitura e grifava palavras com eles. $E$ das medidas fazia separado, trazia uns instrumentos e mostravam o copo medido, por exemplo, e colocava água dentro para eles verem a medida. Mas, desse jeito foi muito bom, sabe. Para mim, principalmente, porque a gente começa a ver a articulação entre os conteúdos, e percebe que trabalhá-los juntos faz mais sentido do que separado. As vezes a gente acha, ah vai virar uma salada de frutas ficar misturando Português com Matemática. Mas, nessa atividade, agora não vejo mais trabalhando separado. Estranho né? Como nós mudamos o olhar para nossa prática depois de conhecer o DUA. Eu amei de verdade essa aula, e ver a APA6 interessada, dando opinião, ajudando, querendo entender, todos eles. Foi muito satisfatório perder, entre aspas, tanto tempo no planejamento e ver uma aula assim tão bonita sabe. Bonita porque eles aprenderam de verdade. Foi significativo para eles. Estou muito feliz com o resultado.

Para P2B, a implementação dos princípios do DUA favoreceu a organização de atividades promovendo uma aprendizagem significativa do conteúdo para os alunos, em especial para aqueles com NEE, corroborando com ideias defendidas por Zerbato e Mendes (2018).

De tal modo, Sebastian-Heredero (2018, p. 3) define que pensar "o planejamento de um currículo inclusivo começa por oferecer algo que é útil para eles e aplicável no seu dia a dia”. Assim, conforme a proposta do DUA no momento de apresentação do conteúdo e nas atividades, o professor deve buscar práticas que promovam essa aproximação com a utilidade do conteúdo da aula, ou seja, a vivência na prática social do aluno (CAST, 2011). 


\title{
iii) Desenvolvimento das estratégias formativas junto a P4A
}

P4A, licenciada em Pedagogia, tinha 23 anos de idade e 6 anos de atuação na Educação Infantil e estava pela primeira vez atuando nos anos iniciais do Ensino Fundamental.

Observamos, ao longo do processo formativo, que $\mathrm{P} 4 \mathrm{~A}$, a docente mais jovem e com menos experiência, demonstrou dificuldade acentuada em relação aos conteúdos curriculares e pedagógicos, ou seja, não demonstrava domínio conceitual em relação aos conteúdos a serem trabalhos e desconhecia estratégias pedagógicas voltadas aos anos iniciais do Ensino Fundamental. Somado a isso, a docente relatou que, em sua formação inicial, os conteúdos de educação inclusiva estudados não lhe possibilitaram desenvolver práticas inclusivas. No episódio abaixo, apresentamos uma participação colaborativa que ilustra a orientação da pesquisadora e o auxílio para a implementação de práxis inclusivas em sua sala de aula.

\section{Quadro 3: Episódio de participação colaborativa com $\mathrm{P} 4 \mathrm{~A}$}

\author{
Data: 29/05/2019 \\ Envolvidos na situação: Professora do $4^{\circ}$ ano A (P4A) e Pesquisadora (P).
}

Situação: Em sala de aula. Conteúdo: Adição e subtração (Matemática). P4A pede para que os alunos, em duplas, resolvam as operações registradas no quadro usando o caderno. Enquanto os alunos realizam a atividade, $\mathrm{P} 4 \mathrm{~A}$ a registra no diário de classe. $\mathrm{P}$ anda pela sala observando a realização da atividade e percebe que PAEE8 e PAEE9 estão sentadas juntas e ambas têm muita dificuldade para realizá-las sozinhas. $\mathrm{P}$ auxilia na realização da primeira operação usando lápis de cor para adição e subtração de quantidade. $\mathrm{P}$ se dirige até P4A e diz: "Oi P4A, estava ali com as meninas e estava percebendo que elas têm bastante dificuldade. P4A diz: "E como! Elas têm mesmo". P orienta: "Então, o que você acha de organizar outras duplas, para que outros alunos possam cooperar na realização da atividade com elas. Quem dos alunos seus aqui, gosta de ajudar?" P4A responde: "Dá sim. A4 e A12 gostam. Terminam e já correm querer ajudar. E eles ajudam bem. Explicam, sabe?" P sugere: "Perfeito, ótimo. O que você acha? Eles estão juntos. Separe-os e coloque um com a PAEE8 e outro com PAEE9 e peça para eles explicarem como fazer, ajudá-las? O que você acha?" P4A diz: "Acho que dá, sim". P4A segue a orientação e reorganiza as duplas. P4A anda pela sala observando a realização da atividade, auxilia algumas duplas. P4A se dirige até $\mathrm{P}$ e descreve: "P acabei de passar lá, nossa que gracinha a A12 está ajudando certinho, explicando, sabe? E o bom que as duas estão aceitando ajuda, porque quando eu vou, elas querem a resposta, ficam olhando para minha cara e não fazem nada. Entre eles, eles se entendem né?”.

Fonte: Nota de campo da pesquisadora (2019) 
Nesta participação colaborativa com P4A, inicialmente, percebemos que $\mathrm{P} 4 \mathrm{~A}$ ofereceu a possibilidade da realização da atividade em dupla, no entanto, não percebeu que PAEE8 e PAEE9 juntas não poderiam se apoiar para realizar a tarefa, pois ambas apresentavam dificuldades. Neste caso, ao ter como finalidade a aprendizagem dos alunos tornou-se necessário ajudála para que provesse condições de apoio para as alunas, por meio de orientações de colegas colaborativos com maior nível de aprendizagem.

De tal modo, as estratégias implementadas por P4A nesta participação colaborativa enfatizam a aplicação do princípio 3 do DUA, a partir de atividades que promovem o interesse e o engajamento dos estudantes durante a realização das atividades (MEYER; ROSE; GORDON, 2014).

Dentre os planos de aula elaborados e aplicados junto com a P4A, selecionamos o planejamento referente ao conteúdo de Produção de advinhas na disciplina de Língua Portuguesa contendo a seguinte proposta de atividades. Primeiramente, a professora entregou fichas coloridas contendo variadas adivinhas escritas à mão para que os alunos fizessem a leitura e respondessem às questão de adivinha 'O que é o que é?'.

$\mathrm{Na}$ sequência, P4A promoveu uma discussão oral e coletiva para que os alunos demonstrassem o seu conhecimento sobre o tema (advinha) a partir de algumas questões: vocês conseguiram identificar o que entreguei a vocês? Vocês conseguiram descobrir o que é? O que são essas perguntas? Para que elas servem?.

Após isso, a professora organizou a sala e dispôs em cima de sua mesa, no centro da sala, uma caixa encapada com um local para retirar um objeto de dentro sem conseguer ver antes de tirá-lo de dentro da caixa. P4A selecionou alguns objetos escolares que ela tinha na sala de aula como lápis, caderno, apagador, caneta, folha, grampeador, borracha, e os colocou dentro da caixa. Assim, explicou a organização da atividade e convidou um aluno e pediu para que ele colocasse a mão dentro da caixa. Segurando um objeto ele deveria descrever, sem dizer o que, exemplo: é duro, é liso, é leve, tem uma 
ponta, se reportando a um lápis. E com base nessa descrição os colegas da turma deveriam adivinhar sobre qual objeto o aluno estava falando dizendo.

Ao longo da atividade, a docente instigigou os alunos para os detalhes dos objetos e problematizando com eles a perceberam como fazer essa descrição oral de cada objeto, pois o desafio de descobrir sem ver o que é. Ao perceber que os alunos estavam dominando a dinâmica da brincadeira e da importância da descrição, salientou para eles esse aspecto fundamental na produção de adivinhas - a descrição das características de um objeto para que alguém descubra sem ver o que é.

Posteriormente, propôs a construção, em pequenos grupos, de adivinhas (escrita, resposta e ilustração) considerando grupos colaborativos de aprendizagem e a instrução entre pares. Durante a atividade, a docente deu suporte e apoio a cada grupo para organizarem funções dentro do grupo: quem iria escrever, qual objeto iriam usar, quem iria desenhar, quem iria apresentar para turma.

Após a produção e escrita no cartaz por cada grupo, um integrante fez a leitura e a turma foi destacando se as advinhas produzidas pelos alunos eram adequadas, se a dscrição estava pertinente para aquele objeto e dando outras sugestões de características que o grupo não usou.

Considerando os ajustes e orientações da professora e da turma, os grupos reuniram as advinhas produzidas e organizaram um único cartaz que foi exposto no corredor da escola para visualização dos alunos de outras turmas (Ver Figura 3).

Identificamos que, durante a aula, PAEE8, PAEE9 e PAEE10 não careceram de apoio individualizado, pois o suporte explicativo, a apresentação do contéudo e a instrução entre os pares foi suficiente para compreensão do conteúdo e da realização da atividade. Todavia, observamos que APA14, APA15 e APA16 precisaram de apoio no momento de divisão das atividades, e com a mediação da professora nos grupos permitiu que cada estudante entendesse a proposta das atividades (seleção de um objeto, criação da advinha, escrita das características, ilustração por meio de desenho do objeto selecionado 
pelo grupo). Nos chamou atenção que os alunos APA se prontificaram a ilustrar a adivinha criada pelo seu grupo, demonstrando que possuíam habilidade para isso. A professora aproveitou a oportunidade e a disposição destes alunos em colaborar e os convidou para ilustrar de todos os grupos no cartaz coletivo que foi fixado no pátio da escola (Ver Figura 3).

Figura 3: Cartaz com advinhas produzidas pelos alunos do $4^{\mathrm{a}}$ ano $\mathrm{A}$ sob orientação de P4A

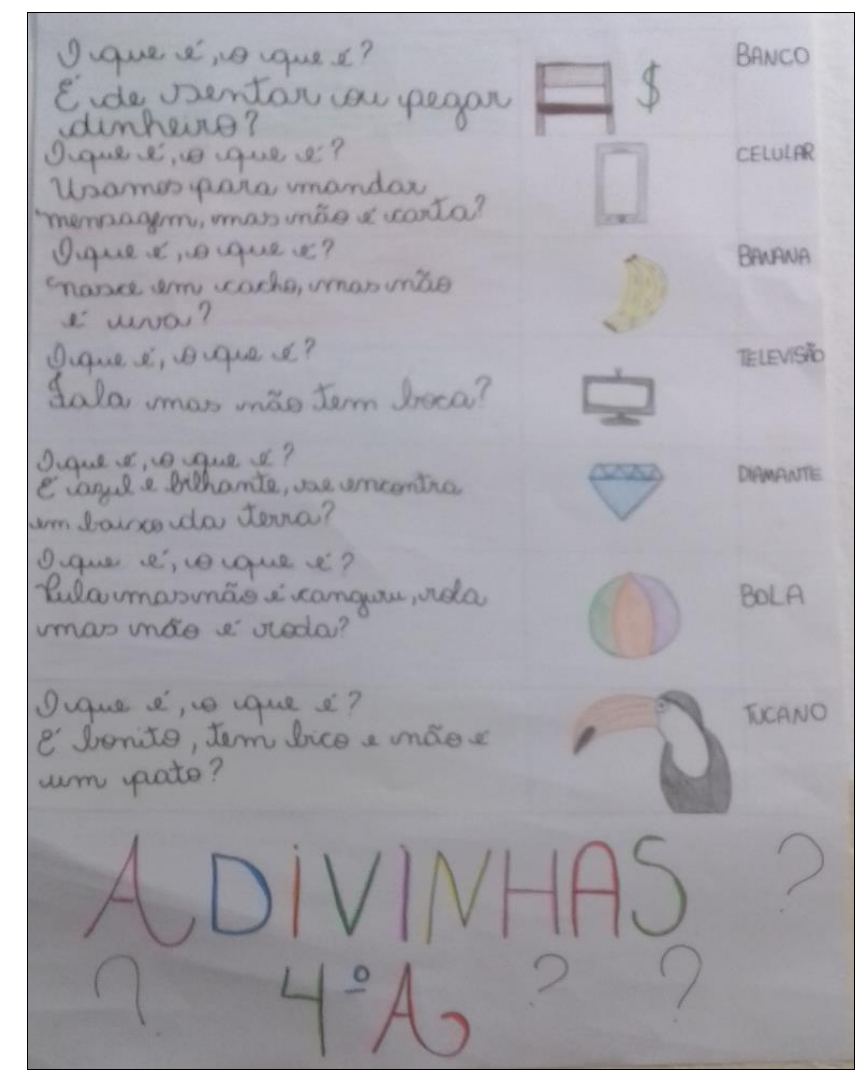

Fonte: Elaborado pelos alunos $4^{\circ}$ ano A sob orientação de P4A (2019)

Assim, P4A durante a aula se reportou a pesquisadora sobre essa situação que ela julgou uma informação importante sobre os alunos, pois já havia observado que, estes três alunos que encontram-se em processo de avaliação de suas NEE, tinham o hábito de ilustrar personagens, fazer com caricaturas e que esta habilidade ela não vinha explorando nas atividades o desenho. P4A avaliou que, nesta aula, eles se engajaram e estiveram interessados em participar, pois iriam ilustrar a advinha criada pelo grupo. 
A docente apontou, no momento de planejamento colaborativo, que estava com dificuldade em entender o conteúdo e como trabalhá-lo com os alunos. Para tanto, a docente com a colaboração da pesquisadora estudou o conteúdo a ser trabalhado com os alunos e depois buscou os recursos didáticos e as estratégias de ensino considerando as NEE identificadas entre seus alunos.

P4A: Você lembra que nem sabia como dar a aula, não é? De verdade, esse conteúdo sabia para mim, mas não para ensinar sabe? Ai a ideia da caixa foi uma boa, porque eles entenderam que a advinha é uma forma de descrever algo sem dizer o que é, leva a curiosidade da gente em descobrir o que é.

Identificamos neste plano de aula, que $\mathrm{P} 4 \mathrm{~A}$ planificou os três princípios do DUA e elaborou atividades que consideraram a necessidade da participação ativa dos alunos. Somado a isso, percebemos que a docente possibilitou formas diferentes de expressão da aprendizagem com a escrita, o desenho e as palavraschave do estudo realizado durante a aula. De tal modo, organizou momentos de atividades coletivas, em grupos e individuais, por meio de possibilidades de ação para a aprendizagem diversificando as estratégias de estudo pelos alunos.

P4A considerou a indicação da proposta didática do DUA na construção dos materiais didáticos que planificaram o processo de aprendizagem dos conceitos de estudo, como no caso do cartaz confeccionado pelos alunos com as advinhas criadas em grupos. Assim, reconhecemos que a docente identificou que seus alunos são diferentes e apresentavam modos diferentes de aprender um conteúdo e, dessa maneira, ao aplicar os princípios do DUA forneceu caminhos diversos para que eles pudessem escolher e atingir o objetivo traçado para a aula (PRAIS, 2020).

Desse modo, ressaltamos que, diferente das demais docentes, com P4A começamos as produções dos planos de aula voltados à implementação do DUA, somente após desenvolver requisitos importantes para o trabalho pedagógico em sala de aula, tais como: o domínio do conteúdo e do plano de aula. No entanto, apesar das dificuldades percebidas ao longo do processo formativo, identificamos que $\mathrm{P} 4 \mathrm{~A}$ evoluiu o entendimento dos conceitos referentes à educação inclusiva e 
frente aos questionamentos da pesquisadora apresentou sugestões criativas e adequadas para o planejamento das aulas e avaliações.

\section{Considerações finais}

Considerando o objetivo deste estudo que consistiu em descrever um processo formativo desenvolvido junto a professoras atuantes nos anos iniciais do Ensino Fundamental, visando o desenvolvimento de práxis inclusivas com base nos princípios do DUA, por meio de uma pesquisa colaborativa, evidenciamos que o aprimoramento do trabalho pedagógico desenvolvido pelas professoras representou uma condição essencial para que elas passassem a promover o processo de inclusão dos alunos com NEE e a aprendizagem de todos os alunos.

Compreendemos que o desenvolvimento das estratégias formativas junto à P2A refletiu em mudanças conceituais e em sua prática pedagógica. A docente que, no início do processo formativo, demonstrava entendimento de que a inclusão estava ligada aos serviços da Educação Especial, desde o diagnóstico a presença do professor de apoio em sala, passou a perceber e identificar o seu papel de identificar as NEE e as singularidades de seus alunos, fato que a levou desenvolver práticas pedagógicas que visavam minimizar barreiras de acesso à aprendizagem.

Percebemos que, ao longo do processo formativo de P2B, as condições que lhe foram propiciadas tais como: descrever as ações educativas; identificar as informações pedagógicas frente ao processo de ensino como conteúdos curriculares; estratégias e recursos utilizados e/ou confeccionados, bem como, o auxílio para refletir sobre o que planejou e o que fez, foram cruciais para que reconstruísse sua atuação profissional e pudesse promover suas práxis pedagógica aliando os conhecimentos teóricos adquiridos ao longo da formação e a implementação destes estudos em sua prática educativa.

P4A nos revelou ao longo de seu processo que a ideia de que os requisitos básicos como domínio de conteúdo e de elaboração de plano de aula quando não são adquiridos na formação inicial, eles devem ser 
revisitados na formação continuada. E percebemos no percurso desta docente maior engajamento com o processo de inclusão educacional, o uso de estratégias diversificadas e o processo de planificação previsto na construção recursos didáticos com os alunos, promovendo uma aprendizagem significativa para seus alunos, em especial, àqueles com NEE.

Constatamos que as professoras colaboradoras aprenderam aplicar os princípios do DUA na prática pedagógica, elaboraram atividades adequadas ao atendimento das NEE de seus alunos, bem como, utilizaram recursos didáticos que favoreceram à aprendizagem de todos os alunos. Foram evidenciadas contribuições advindas do processo formativo subsidiado pelo DUA aliado aos procedimentos da pesquisa colaborativa por meio do aprimoramento na qualidade do ensino em relação a todos os estudantes, e das mudanças ocorridas nos planos de aulas e nas práticas pedagógicas efetivas das docentes.

Percebemos que a metodologia utilizada fundamentada na proposta de colaboração entre pesquisador e professor foi adequada, pois os procedimentos indicados (sensibilização das professoras, identificação das necessidades formativas, programa de formação colaborativa - ciclos de estudos, participação colaborativa, prática reflexiva e planejamento colaborativo, avaliação do processo formativo) favoreceram ao processo de formação permitindo a construção de práxis inclusivas.

Ressaltamos, assim, que a formação docente subsidiada pelos princípios do DUA permite a construção de práxis inclusivas tendo em vista a efetivação de uma educação para todos os alunos, ao promover o acesso e a acessibilidade à escola, ao currículo e à aprendizagem,

\section{Referências}

CAST. Design for Learning guidelines: Desenho Universal para a aprendizagem. Estados Unidos: CAST, 2011.

IBIAPINA, I. M. L. M. Pesquisa colaborativa: investigação, formação e produção de conhecimentos. Brasília: Líber Livro, 2008. 
LUSTOSA, A. V. M. F. A expressão da subjetividade no contexto da educação inclusiva: complexidade e desafios. Obutchéne: Revista de Didática e de Psicologia e Pedagogia, Uberlândia, MG, v. 5, n. 1, p. 114-134, jan/abr, 2019.

MEYER, A.; ROSE, D.; GORDON, D. Universal Design for Learning (UDL). Estados Unidos: CAST, 2002.

MEYER, A.; ROSE, D.; GORDON, D. Desenho universal para a aprendizagem: Teoria e Prática. Wake Field, MA: ELENCO Professional Publishing, 2014.

MORNINGSTAR, M. E.; SHOGREN, K. A.; LEE, H.; BORN, K. Preliminary Lessons about Supporting Participation and Learning in Inclusive Classrooms. Research and Practice for Persons with Severe Disabilities, v.40, n. 3, p.192-210, 2015.

MOURA, M. O. Pesquisa colaborativa: um foco na ação formadora. In: BARBOSA, R. L. L. (Org.) Trajetórias e perspectivas da formação de educadores. São Paulo: Unesp, 2004. (p. 257-284).

NUNES, C.; MADUREIRA, I. Desenho Universal para a Aprendizagem: Construindo práticas pedagógicas inclusivas. Da Investigação às Práticas, v.5, n. 2, p. $126-143,2015$.

OMOTE, S. A formação do professor de educação especial na perspectiva da inclusão. In. BARBOSA, R. L. L. (Org.) Formação de educadores: desafios e perspectivas. São Paulo: Editora UNESP, 2013. (p.153-169).

PRAIS, J. L. S. Das intenções à formação docente para a inclusão: contribuições do Desenho Universal Para a Aprendizagem. Curitiba: Appris, 2017.

PRAIS, J. L. S. Formação de professores para o desenvolvimento de práxis inclusivas baseadas no Desenho Universal para a Aprendizagem: uma pesquisa colaborativa. 2020. 300 fls. Tese (Doutorado em educação) - Centro de Educação, Comunicação e Artes, Universidade Estadual de Londrina, Londrina, 2020.

SÁNCHEZ, P. A. A educação inclusiva: um meio de construir escola para todos no século XXI. Inclusão - Revista da educação especial, out., p. 7-18, 2005.

SEBASTIAN-HEREDERO, E. Escola inclusiva: um novo olhar para o currículo de uma escola para todos. Revista Eletrônica de Educação, v. 1, n. 1, p. 68-77, 2018.

VITALIANO, C. R. Formação de professores de Educação Infantil para inclusão de alunos com necessidades educacionais especiais: uma pesquisa colaborativa.

Revista Pro-Posições, v.30, Campinas, jul, 2019.

ZERBATO, A. P.; MENDES, E. G. Desenho universal para a aprendizagem como estratégia de inclusão escolar. Revista Educação, Unisinos, v. 22, n. 2, 2018. 